\title{
Environmental contaminants and male infertility: Effects and mechanisms
}

\author{
Vaithinathan Selvaraju $^{1}$ (D) | Saradha Baskaran ${ }^{2}$ (D) | Ashok Agarwal ${ }^{2}$ (i) $\mid$ Ralf Henkel $^{2,3}$
}

${ }^{1}$ Department of Nutrition, Dietetics and Hospitality Management, Auburn University, Auburn, AL, USA

${ }^{2}$ American Center for Reproductive Medicine, Cleveland Clinic, Cleveland, $\mathrm{OH}$, USA

${ }^{3}$ Department of Medical Bioscience, University of the Western Cape, Bellville, South Africa

Correspondence

Ashok Agarwal, American Center for Reproductive Medicine, Cleveland Clinic, Mail Code X-11, 10681 Carnegie Avenue, Cleveland, OH 44195, USA.

Email: agarwaa@ccf.org

\begin{abstract}
The escalating prevalence of male infertility and decreasing trend in sperm quality have been correlated with rapid industrialisation and the associated discharge of an excess of synthetic substances into the environment. Humans are inevitably exposed to these ubiquitously distributed environmental contaminants, which possess the ability to intervene with the growth and function of male reproductive organs. Several epidemiological reports have correlated the blood and seminal levels of environmental contaminants with poor sperm quality. Numerous in vivo and in vitro studies have been conducted to investigate the effect of various environmental contaminants on spermatogenesis, steroidogenesis, Sertoli cells, blood-testis barrier, epididymis and sperm functions. The reported reprotoxic effects include alterations in the spermatogenic cycle, increased germ cell apoptosis, inhibition of steroidogenesis, decreased Leydig cell viability, impairment of Sertoli cell structure and function, altered expression of steroid receptors, increased permeability of blood-testis barrier, induction of peroxidative and epigenetic alterations in spermatozoa resulting in poor sperm quality and function. In light of recent scientific reports, this review discusses the effects of environmental contaminants on the male reproductive function and the possible mechanisms of action.
\end{abstract}

\section{KEYWORDS}

endocrine disruptors, environmental contaminants, male infertility, spermatogenesis, steroidogenesis

\section{1 | INTRODUCTION}

The global incidence of infertility has risen to $15 \%$ in contrast to $7 \%-8 \%$ in the early 1960s (Mascarenhas, Flaxman, Boerma, Vanderpoel, \& Stevens, 2012). Over the past several decades, a significant deterioration in male reproductive health has been reported in association with increased industrialisation, which has contributed to a massive release of synthetic pollutants into the environment (Rim, 2017; Skakkebaek et al., 2016). The concerns over declining male reproductive health were elicited by one of the landmark publications by Carlsen et al., which revealed a worldwide reduction in the average sperm count to half between 1940 and 1990 (Carlsen, Giwercman, Keiding, \&
Skakkebaek, 1992). These findings prompted several scientists, mainly Swan et al. to re-evaluate the trend in semen quality over time in different regions throughout the world and eventually confirmed a significant decrease in sperm concentration in western countries (Swan, Elkin, \& Fenster, 1997). Incidentally, a parallel increase in the occurrence of testicular cancer and congenital abnormalities (cryptorchidism and hypospadias) were reported in several countries (Ferguson \& Agoulnik, 2013; Hutson, 2000). These observations prompted researchers to explore the potential role of common environmental factors in causing a decline in male reproductive health.

In 1993, it was hypothesised that the growing incidence of male reproductive anomalies could be due to exposure to chemicals possessing oestrogenic property (Sharpe \& Skakkebaek, 1993). 
Subsequently, numerous studies reported defects in the reproductive ability of wildlife species such as fish, birds, alligators, turtles, salamanders, frogs, toads and Florida panthers, which were exposed to specific industrial chemicals directly or indirectly during prenatal or post-natal period (Barakat, Seymore, Lin, Park, \& Ko, 2019; Doyle, Bowman, Windell, McLean, \& Kim, 2013; Fang et al., 2018; Unuvar $\&$ Buyukgebiz, 2012). The reported reproductive defects in wildlife included, but were not limited to, decreased hatching, gonadal morphological abnormalities, eggshell thinning, demasculinisation and feminisation of the male offspring, altered circulating hormone concentration, impaired viability of offspring and population decline (Anwer, Chaurasia, \& Khan, 2016). In addition to several wildlife incidents, a substantial number of epidemiological reports on the declining trends in male reproductive health revealed a strong correlation between exposure to environmental contaminants and reduced semen quality and an increased incidence of cryptorchidism (Street et al., 2018; Woodruff, Carlson, Schwartz, \& Giudice, 2008). Occupational exposure to hazardous chemicals has been reported to cause recurrent abortion, congenital defects, stillbirth, testicular dysfunction, sperm abnormalities and impaired male fertility (Kumar, 2018).

Environmental contaminants comprise a wide variety of chemicals such as pesticides, herbicides, fertilisers, plasticisers and surfactants, effluents released from the production units, polychlorinated biphenyls (PCBs), polycyclic aromatic hydrocarbon (PAH) and heavy metals (Sprovieri et al., 2007). Approximately more than eighty thousand new chemicals have been released into the environment in the past hundred years. They are ubiquitously distributed in the ecosystem and find their way into human life through the food chain. Most of the environmental contaminants have been found in sediment, water, wastewaters as well as in human and wildlife food materials at either low or high levels (Ferrara, Ademollo, Delise, Fabietti, \& Funari, 2008; Guenther et al., 2002; Di Nisio \& Foresta, 2019; Rodriguez-Mozaz, Marco, Lopez de Alda, \& Barceló, 2004; Tavares, Escada-Rebelo, Correia, Mota, \& RamalhoSantos, 2016). In fact, studies have revealed the presence of environmental contaminants in the Arctic region (known as a natural milieu due to its remoteness), which indicates the transport of environmental contaminants to the northern Arctic region by water currents (Carlsson et al., 2018).

The universal presence of environmental contaminants and their ability to intervene with male reproductive development and functions have been well documented (Jeng, 2014; La Rocca et al., 2015) Several animal studies have been conducted to examine the deleterious effects of various environmental toxicants on male fertility and decipher their possible mechanism(s) of action (Akarca-Dizakar et al., 2019; Albert, Nardelli, Lalancette, Hales, \& Robaire, 2018; Aydin \& Erkan, 2017; Campos et al., 2019; Kim, Cheon, Choi, \& Lee, 2019; Kolatorova et al., 2018). The focus of this review is to shed light on the impact of environmental contaminants on male reproduction and the underlying mechanism of action based on the recent scientific data available.

\section{Key points}

- Environmental contaminants play a significant role in the growing incidence of male infertility.

- Various environmental contaminants impair testicular steroidogenesis via direct or receptor-mediated inhibition and/or inducing oxidative stress.

- Environmental contaminants disrupt spermatogenesis, Sertoli cell function and integrity of the blood-testis barrier.

- Epigenetic mechanisms are involved in the transgenerational inheritance of reproductive abnormalities induced by environmental contaminants.

\section{Potential areas of research}

- Epidemiological studies have correlated the concentrations of environmental contaminants with poor sperm quality, which warrants for establishing predictive biomarkers to identify human exposure to contaminants.

- Epigenetic and transgenerational epigenetic markers for environmental exposure can be deduced in the future by analysing the sperm samples of occupationally exposed subjects and their offspring.

- As we are exposed to a mixture of environmental contaminants in our day to day life, studies focusing on the synergistic effects of various contaminants would be of added value in the current scenario.

\section{2 | IMPACT OF ENVIRONMENTAL CONTAMINANTS ON TESTICULAR FUNCTIONS}

Some of the environmental contaminants are known as endocrine disruptors (EDs) due to their capability to mimic endogenous hormones and interrupt the endocrine systems (Rehman et al., 2018). They exhibit oestrogenic and/or antiandrogenic properties and thereby act as an agonist or antagonist of endogenous hormones in the body. Though environmental contaminants affect various organs, the testis is known to be one of the most vulnerable targets. The increased expression of oestrogen receptors (ER) in the testis and the regulatory influence of oestrogen on testicular spermatogenesis and steroidogenesis could be important contributing factors for the increased susceptibility of the testis to the detrimental effects of environmental contaminants.

\section{1 | Environmental contaminants and spermatogenesis}

Spermatogenesis is an intricate process stringently regulated by various factors and extremely infringed by environmental 
contaminants due to its negative influence on germ cell proliferation and differentiation, resulting in male infertility (Smith \& Walker, 2014). Exposure to environmental chemicals that mimic oestrogen has been reported to impair spermatogenesis in animals and humans (Jeng, 2014; McLachlan, 2016; Sweeney, Hasan, Soto, \& Sonnenschein, 2015; Tavares et al., 2016). The oestrogenic effects of bisphenol A (BPA) measured in fertile and infertile Italian men from metropolitan, urban and rural areas showed an increased expression of $E R \alpha$ and $E R \beta$ with other nuclear receptors. In addition, the expression of ER showed a positive association with BPA levels in infertile men from the metropolitan area (La Rocca et al., 2015). On the other hand, maternal exposure of BPA significantly affects first filial generation (F1 generation) males' serum testosterone and oestrogen levels while increasing the expression levels of $E R \alpha$ and $E R \beta$ in testicular tissue at post-natal day (PND) 21 and 56 (Wei et al., 2019). Fenvalerate, a synthetic pyrethroid insecticide, has been reported to disturb the spermatogenic cycle in pubertal rats by increasing stage-specific (I-V) germ cell apoptosis (Zhang et al., 2018). Assessment of reproductive toxicity of a brominated organochlorine nematicide, 1,2 dibromo-3-chloropropane (DBCP) and 2-bromopropane (2-BP) using an in vitro human spermatogenic model demonstrated reduced germ cell viability through apoptosis and generation of reactive oxygen species (ROS) resulting in an oxidised cellular milieu (Easley et al., 2015). Governini et al. (2015) examined the presence of perfluorinated compounds (PFC), an organofluorine, in blood and semen samples in correlation with sperm quality, chromosomal segregation and DNA fragmentation (Governini et al., 2015). The study revealed alterations in sperm parameters along with an increased rate of sperm aneuploidy and DNA fragmentation index in PFC positive subjects. These findings suggested that PFC may have adverse consequences on spermatogenesis by disturbing both meiotic segregation and DNA integrity (Governini et al., 2015).

Within the testicular environment, Sertoli cells serve as the nurturing cells and support the developing germ cells through different stages of spermatogenesis. The Sertoli cell to germ cell ratio plays a vital role in the regulation of the spermatogenic energy metabolism and sustaining normal spermatogenesis (Rebourcet et al., 2017). The commonly reported histological changes in the testis of animal models exposed to various toxicants mainly include seminiferous epithelium sloughing (detachment and separation of germ cells from underlying epithelium) and Sertoli cell vacuolisation (Johnson, 2014). Cypermethrin, a synthetic insecticide, caused a substantial rise in epithelial height and dedifferentiation of Sertoli cells in the testis thereby, impairing the structural and functional integrity of Sertoli cells of the adult mouse (Rodríguez et al., 2017). Apart from these degenerative changes, environmental contaminants are also known to impair the molecular signalling pathways between Sertoli and germ cells (Gao, Mruk, \& Cheng, 2015). The organochlorine pesticide, endosulfan, caused Sertoli-germ cell degeneration in exposed rats due to increased oxidative stress and associated activation of apoptotic pathway resulting in a decreased production of quality gametes (Rastogi, Narayan, Saxena, \& Chowdhuri, 2014).
A study on the effects of 2,2-bis(4-chlorophenyl)-1,1-dichloroethylene (DDE), an organochlorine pesticide and an ethylene metabolite of DDT, on the bioenergetics parameters of testicular mitochondria, revealed a significant reduction in mitochondrial function and its possible implication on the bioenergetics of spermatogenesis and male fertility (Mota et al., 2011). Mice exposed to a low dose of cadmium chloride $\left(\mathrm{CdCl}_{2}\right)$ significantly altered the immunological microenvironment in the testis as evidenced by increased expression of interleukin (IL)-6, tumour necrosis factor- $\alpha$ (TNF- $\alpha$ ) and IL-1 $\beta$ resulting in increased vulnerability to testicular autoimmunity (Ogawa et al., 2013). Geoffroy-Siraudin et al. used a rat seminiferous tubule culture model to demonstrate the dose-dependent toxic effects of hexavalent chromium on meiotic cells (Geoffroy-Siraudin et al., 2010). Among their prominent observations were a decreased number of late spermatocytes and round spermatids along with an increased percentage of synaptonemal complex abnormalities (Geoffroy-Siraudin et al., 2010). More evidence on the deleterious effects of environmental contaminants on spermatogenesis is presented in Table 1.

\subsection{Environmental contaminants and steroidogenesis}

Leydig cells present in the interstitial space are the primary cells involved in the biosynthesis of testosterone under the influence of luteinising hormone (LH) (Odermatt, Strajhar, \& Engeli, 2016; Tremblay, 2015). Testosterone plays a vital role in the initiation and maintenance of spermatogenesis, differentiation of male genital organs and development of secondary sexual characteristics. Any factor that affects Leydig cell viability and/or interferes with testicular steroidogenesis can lead to the disruption of endocrine regulation of spermatogenesis and impairs fertility. Environmental contaminants are known to impair steroidogenesis by exerting an inhibitory effect on one or more steps in the steroidogenic pathways (Aydin \& Erkan, 2017; Maske, Dighe, Mote, \& Vanage, 2020; Singh \& Singh, 2019) (Table 2).

Studies reveal that exposure to BPA and triclosan results in decreased expression of $\mathrm{LH}$ receptor with an associated reduction in adenylate cyclase activity, leading to decreased synthesis of cAMP (Kumar, Balomajumder, \& Roy, 2008; Wisniewski et al., 2015). Exposure of preimplantation embryos to BPA has been reported to reduce the levels of steroidogenic acute regulatory protein (StAR) and $\mathrm{P}^{4} 5 \mathrm{O}_{\text {scc }}$ leading to reduced testosterone synthesis and resulting in retardation of testicular development in mice (Hong et al., 2016). A similar kind of effect on StAR and $\mathrm{P}^{450} \mathrm{ssc}_{\text {sc }}$ mRNA expression has been noted in guinea pigs treated with fluoride and aluminium (Dong et al., 2016). Mouse Leydig cells exposed to Aroclor 1,242, a commercial mixture of PCBs, resulted in reduced Leydig cell viability and impaired testosterone biosynthesis by inhibiting two steroidogenic enzymes ( $3 \beta$-hydroxysteroid dehydrogenase [HSD] and 17 $\beta$-HSD) (Aydin \& Erkan, 2017). In adult male rats, organochlorines, namely lindane and methoxychlor, have been reported to alter the testicular levels of StAR protein, androgen-binding 
TABLE 1 Effect of environmental contaminants on spermatogenesis




TABLE 2 Effect of environmental contaminants on steroidogenesis

\begin{tabular}{|c|c|c|c|}
\hline Toxicant (s) & Observed effects & Study model & Reference \\
\hline \multicolumn{4}{|l|}{ Herbicide } \\
\hline \multicolumn{4}{|l|}{ Fungicide } \\
\hline Triphenyltin chloride (TPT) & $\begin{array}{l}\text { In vivo treatment reduced the testosterone level and lowered StAR, } \\
H s d 3 b 1 \text {, and } H s d 17 b 3 \text { mRNA levels. }\end{array}$ & Rat in vivo, in vitro & (Li et al., 2018) \\
\hline \multicolumn{4}{|l|}{ Plasticisers } \\
\hline Bisphenol A (BPA) & Reduced Leydig cell capacity and decreased sperm count & $\begin{array}{l}\text { Human serum } \\
\text { samples in vivo }\end{array}$ & $\begin{array}{l}\text { (Adoamnei } \\
\text { et al., 2018) }\end{array}$ \\
\hline Phthalate mixtures & $\begin{array}{l}\text { Prenatal exposure down-regulated the expression of testicular } \\
\text { steroidogenic genes }\end{array}$ & Mice in vivo & $\begin{array}{l}\text { (Barakat } \\
\text { et al., 2019) }\end{array}$ \\
\hline $\begin{array}{l}\text { Di-(2-ethylhexyl) phthalate } \\
\text { (DEHP) and diethyl phthalate } \\
\text { (DEP) }\end{array}$ & $\begin{array}{l}\text { Affected foetal Leydig cell (aggregation and cell size) and StAR } \\
\text { expression }\end{array}$ & Rat in vivo & (Hu et al., 2018) \\
\hline \multicolumn{4}{|l|}{ Industrial influence } \\
\hline $\begin{array}{l}\text { Aroclor 1,242 (Polychlorinated } \\
\text { biphenyl) }\end{array}$ & $\begin{array}{l}\text { Reduced Leydig cell viability, increased ROS, inhibited steroidogenic } \\
\text { enzymes } 3 \beta \text {-hydroxysteroid dehydrogenase [HSD] and } 17 \beta \text {-HSD }\end{array}$ & $\begin{array}{l}\text { Leydig cells in } \\
\text { vitro }\end{array}$ & $\begin{array}{l}\text { (Aydin \& } \\
\text { Erkan, 2017) }\end{array}$ \\
\hline \multicolumn{4}{|l|}{ Air pollution } \\
\hline $\mathrm{PM}_{2.5}$ & $\begin{array}{l}\text { Decreased levels of testosterone biosynthesis-related genes, StAR, } \\
\text { P450scc, P450arom, ER and FSHR. }\end{array}$ & Mice in vivo & (Yang et al., 2019) \\
\hline
\end{tabular}

protein (ABP) and activities of $3 \beta-\mathrm{HSD}$ and $17 \beta-\mathrm{HSD}$ with associated increase in the levels of $\mathrm{H}_{2} \mathrm{O}_{2}$ (Saradha, Vaithinathan, \& Mathur, 2008; Vaithinathan, Saradha, \& Mathur, 2008). The inhibitory effects of these organochlorines on steroidogenesis was reported to be due to impaired Sertoli cell function and increased generation of ROS associated with oxidative stress (Saradha et al., 2008; Vaithinathan et al., 2008). Chronic exposure to arsenite, a natural environmental contaminant, has been reported to activate the immunological responses of macrophages in the testis, which affects testosterone metabolism and inhibits steroidogenesis (de Araujo Ramos, Diamante, de Almeida Lamas, Dolder, \& de Souza Predes, 2017).

Numerous studies have demonstrated the deleterious effects of phthalates, the most commonly used plasticiser, on Leydig cell steroidogenesis using a rodent model (Rehman et al., 2018; Svechnikov et al., 2016; Wang, Ni, et al., 2019). The study conducted with human organo-culture adult testis revealed the inhibitory effect of di-(2-ethylhexyl) phthalate (DEHP) and mono-(2-ethylhexyl) phthalate (MEHP), on steroidogenesis, notably androgen synthesis in testicular tissue (Desdoits-Lethimonier et al., 2012). In fact, epidemiological studies have demonstrated an inverse correlation between serum testosterone concentration and urinary levels of MEHP (Svechnikov et al., 2016).

\section{3 | Environmental contaminants and blood- testis barrier}

The blood-testis barrier (BTB) is comprised of tight junctions (TJ), gap junctions and adherent junctions (AJ) between the Sertoli cells (Mruk \& Cheng, 2015). The BTB segregates the seminiferous epithelium into two 
sections, namely the basal and the apical compartments. Post-meiotic germ cell development takes place in the apical compartment, while spermatogonial renewal and differentiation up to pre-leptotene spermatocytes occur in the basal compartment of the epithelium (Cheng \& Mruk, 2011; Xiao, Mruk, Wong, \& Cheng, 2014). Furthermore, the BTB creates an ideal milieu for meiosis and development of post-meiotic germ cells in isolation from the systemic circulation, which would otherwise result in the development of anti-sperm antibodies (Islam et al., 2017). The presence of multiple junction types has been attributed to the inherent tightness of the BTB. Ironically, the BTB is one of the primary targets for various environmental toxicants (Chianese et al., 2018; de Freitas et al., 2016; Qiu et al., 2016; Zhou et al., 2020). Exposure to the commercial PCB mixture, Aroclor 1,254 resulted in disruption of the BTB in treated rats and cultured Sertoli cells by promoting endocytosis and degradation of junctional proteins via the p38 mitogen-activated protein kinase (MAPK) pathway (Jia et al., 2017). Also, $\mathrm{CdCl}_{2}$ has been reported to disrupt the BTB via the $\mathrm{p} 38 \mathrm{MAPK}$ signal transduction pathway (Siu, Mruk, Porto, \& Cheng, 2009). In another study, in vivo and in vitro models were used to demonstrate the effect of perfluorooctane sulphonate (PFOS), a ubiquitous pollutant, on the BTB. Exposure to PFOS resulted in increased BTB permeability, p38/ activating transcription factor 2 (ATF2) phosphorylation and matrix metalloproteinase 9 expressions with a parallel decrease in the expression of BTB proteins (occludin and connexin 43) highlighting the role of p38/ATF2/MMP9 signalling pathway in PFOS-mediated BTB disruption (Qiu et al., 2016). Effects of BPA and $\mathrm{CdCl}_{2}$ on cultured human Sertoli cell revealed perturbation of Sertoli cell adhesive function by inducing alterations in the F-actin network (Xiao et al., 2014). Exposure of human Sertoli cells to monobutyl phthalate (MBP), an endocrine disruptor, resulted in reduced expression of junctional proteins occludin, ZO-1, $\beta$-catenin and androgen receptor (AR) (de Freitas et al., 2016). The study revealed that MBP alters the structural and functional integrity of BTB via the AR-dependent pathway (de Freitas et al., 2016). This report points to the increased susceptibility of the junctional proteins to the detrimental effects of various environmental toxicants.

Dankers et al. reported that some of the endocrine disruptors such as BPA, tetrabromobisphenol A (TBBPA), DEHP, MEHP, perfluorooctanoic acid (PFOA) and PFOS interfere with ATP-binding cassette transporters in the BTB resulting in decreased testosterone secretion in murine Leydig cells (MA-10) (Dankers et al., 2013). A recent report shows chronic exposure of BPA in rats via the placenta, over lactation and at weaning increased the body weight in the male offspring at PND 45 and affected the first round of spermatogenesis by damaging BTB, DNA and decreasing the expression of protein sirtuin 1(SIRT1) (Chianese et al., 2018).

\section{3 | IMPACT OF ENVIRONMENTAL CONTAMINANTS ON EPIDIDYMAL FUNCTIONS}

The spermatozoa exiting the testis are immotile and lack the ability to fertilise an egg. The epididymis provides an ideal milieu for sperm maturation and storage (in the distal cauda). Spermatozoa acquire forward motility as well as fertilising ability during their transit through the epididymis (Sullivan \& Mieusset, 2016). The epithelium of the epididymis is characterised by a unique set of tight junctions that contribute to the formation of a blood-epididymis barrier, which is responsible for the maintenance of a distinct intraluminal microenvironment. In fact, the proteins and enzymatic composition of the intraluminal fluid continuously change along the epididymis from caput to cauda, which facilitates the essential morphological and biochemical changes associated with sperm maturation. Therefore, any factor that disrupts the structure and/function of the epididymis can result in the impairment of sperm maturation and hence, affect male fertility.

The most commonly reported effects of environmental contaminants on the epididymis include a reduction in the epididymal weight, degenerative changes in the epithelium and decreased epididymal sperm count (Li et al., 2019). Exposure of adult rats to a mixture of heavy metal cadmium and pesticide diazinon resulted in significant structural changes in epididymal tissue such as epithelial thickening, necrosis of epithelial cells, constriction of blood vessels, interstitial oedema and infiltration of the mononuclear cell (Adamkovicova et al., 2014). A recent study investigated the juvenile toxicity of inorganic arsenic in prepubertal rats following exposure to dose levels ( 0.01 and $10 \mathrm{mg} / \mathrm{L}$ ) that reflect realistic environmental concentrations. The study demonstrated disruption of testicular and epididymal histoarchitecture and inflammatory infiltration, reduced epididymal sperm concentration in the lumen and alterations in the expression of androgen receptor in the epididymis (da Cunha de Medeiros et al., 2019).

Maternal exposure to EDs such as BPA has been reported to disrupt reproductive functions in the offspring by increasing sperm reserves and transit time in cauda epididymis leading to sperm abnormalities (Campos et al., 2019). Altered expression of tight junctional proteins, occluding and ZO-1 has been reported in mice exposed to PCB (Cai, Wang, Huang, Chen, \& Zuo, 2013). Similar effects have been documented in rodents exposed to BPA along with significant damage to epididymal tissue and abnormalities in the sperm head and tail (Akarca-Dizakar et al., 2019).

\section{4 | IMPACT OF ENVIRONMENTAL CONTAMINANTS ON PROSTATE AND SEMINAL VESICLES}

Seminal vesicle and prostate are the two main accessory sex glands that contribute $90 \%$ of the seminal plasma content, with the remaining $10 \%$ coming from the epididymis and testis (Verze, Cai, \& Lorenzetti, 2016). Seminal plasma serves as a medium to protect, nourish and carry spermatozoa after ejaculation up to fertilisation and contains essential modulators of sperm function. Seminal levels of environmental contaminants correlate negatively with sperm quality and biochemical markers of accessory sex glands in infertile men (Pant et al., 2003; Pant, Mathur, Banerjee, Srivastava, \& 
Saxena, 2004; Vitku et al., 2016). Pant et al. (2004) reported higher concentrations of chlorinated pesticides [isomers of hexachlorocyclohexane $(\mathrm{HCH})$ and metabolites of dichlorodiphenyltrichloroethane (DDT)] in the semen of infertile men when compared to fertile subjects (Pant et al., 2004). Furthermore, the study revealed a direct correlation between seminal concentrations of chlorinated pesticides and fructose in infertile subjects. Fructose is crucial for sperm metabolism and motility, while seminal levels of fructose are suggestive of decreased utilisation by spermatozoa resulting in diminished motility. Pant et al. (2004) also reported a negative association between seminal concentration of chlorinated pesticides $(\alpha-\mathrm{HCH}$, $\beta-\mathrm{HCH}$ and $p p^{\prime}-\mathrm{DDE}$, a metabolite of DDT) and prostatic markers, namely acid phosphatase and $\gamma$-glutamyl transpeptidase, which indicated decreased prostatic function (Pant et al., 2004). A similar association has been shown between seminal plasma levels of heavy metals (lead and cadmium), and seminal vesicle and prostatic markers in infertile men (Pant et al., 2003).

Several contaminants have been shown to reduce the weight of seminal vesicles and prostate by either directly inducing degenerative histoarchitectural changes or indirectly via inhibition of the testicular production of testosterone, the major growth factor of accessory sex glands (Hou et al., 2020; Riad, Abd-Rabo, Abd El Aziz, El Behairy, \& Badawy, 2018; Sugantha Priya et al., 2017). In a rodent model, exposure to BPA and octylphenol (OP) resulted in atrophic tubules and intraepithelial neoplasia of the prostate gland (Ahbab, Barlas, \& Karabulut, 2017), while cadmium-induced vasoconstriction and degenerative cellular changes in the seminal vesicles and prostate (Sayed, Hassanein, \& Senosy, 2014). Prenatal exposure to a mixture of phthalate, equivalent to human exposure levels, resulted in smaller gonads, prostates and seminal vesicles in F1 male mice with drastically decreased expression of steroidogenic genes and serum testosterone levels (Barakat et al., 2019).

\section{5 | EFFECT OF ENVIRONMENTAL CONTAMINANTS ON SPERM FUNCTION}

Male infertility is evaluated based on semen quality such as sperm density, motility, vitality and morphology. During the past few decades, the decrease in human semen quality and increasing prevalence of cryptorchidism in infants has been correlated with exposure to environmental contaminants. Lea et al. (2016) observed a decline in sperm quality in breeding dogs for the past 26 years (1988-2014) and increased number of cryptorchidism in male offspring from 1995 to 2014 (Lea et al., 2016). Furthermore, the study revealed the presence of phthalate (DEHP) and organochlorine (PCB 153) in adult dogs' testes and commercial dog foods at a disturbing level (Lea et al., 2016). In vitro exposure of human and dog spermatozoa to PCB153, and DEHP at different concentrations resulted in increased DNA fragmentation and decreased motility (Sumner, Tomlinson, Craigon, England, \& Lea, 2019). Numerous epidemiological studies have demonstrated the negative correlation between seminal or urinary level of environmental contaminants (such as PCB, triclosan,
BPA, lead) and low semen quality in men exhibiting alterations in sperm concentration, total sperm count, motility, viability and morphology (Albert et al., 2018; Mantzouki et al., 2019; Nassan et al., 2019; Paul et al., 2017; Ren et al., 2019). Wang et al. reported elevated urinary phthalates associated in men with poor sperm quality caused by metabolic disorders of seminal plasma mostly linked to PUFA and acylcarnitine (Wang, Wu, et al., 2019).

In vitro exposure of rodent spermatozoa to different concentrations of BPA inhibited sperm motility and motion kinematics through a significant reduction in ATP levels in spermatozoa (Rahman et al., 2015). Furthermore, higher concentrations of BPA increased the tyrosine phosphorylation of sperm proteins by regulating protein-dependent kinase (PKA) activity, which mediates acrosome reaction. BPA-mediated changes in fertility-related proteins induced premature acrosome reaction, resulting in poor fertilisation, and compromised embryonic development (Rahman et al., 2015). In vivo exposure to BPA has also been reported to adversely affect sperm quality, functions and morphology of exposed mice by inducing oxidative stress and DNA damage in spermatozoa (Ikhlas \& Ahmad, 2020). In vitro treatment of human spermatozoa with two different phthalates, di-butyl phthalate (DBP) and mono-n-butyl phthalate (MBP), showed a detrimental effect on sperm motility, penetration capability and capacitation along with suppressed sperm tyrosine phosphorylation, which is involved in the regulation of sperm functions (Xie et al., 2019). In vivo exposure of DBP from medications of inflammatory bowel disease (IBD) resulted in differential expression of numerous sperm RNA elements as well as activation of oxidative stress and DNA damage pathways in spermatozoa of patients with IBD (Estill, Hauser, Nassan, Moss, \& Krawetz, 2019). Chlorothalonil, a broad-spectrum fungicide, decreased boar spermatozoa motility and increased apoptosis by altering mitochondrial membrane potential (Zhang et al., 2019).

\section{6 | EPIGENETIC EFFECTS OF ENVIRONMENTAL CONTAMINANTS ON MALE REPRODUCTION}

Growing evidence indicates that epigenetic alterations can be an essential mechanism in mediating the impact of environmental contaminants on male reproduction (Donkin \& Barres, 2018). The epigenetic mechanism includes DNA methylation, modification of histones and miRNAs gene expression (Dada et al., 2012; Muratori \& De Geyter, 2019). Pubertal exposure to zearalenone (ZEA), an $E D$, has been reported to disturb the meiosis process and signalling pathways in spermatogenesis, leading to diminished semen quality in mice (Gao et al., 2015). Furthermore, DNA methylation markers $5 \mathrm{mC}$ and $5 \mathrm{hmC}$ were decreased, and histone methylation marker H3K27 was increased along with the decreased expression of testicular ER $\alpha$ in mice exposed to ZEA (Gao et al., 2015; Men et al., 2019). These studies revealed the crucial role of interactions between the oestrogen signalling pathway and genetic and epigenetic pathways in mediating the adverse effects of ZEA on spermatogenesis (Gao 
et al., 2015; Men et al., 2019). Kim et al. reported nonylphenol induced pathophysiological abnormalities in testis and epididymis of F2 mice, which were suggested to be a result of epigenetic reprogramming by nonylphenol exposure (Kim et al., 2019).

Developmental exposure to environmental contaminants can lead to the transmission of epigenetic alterations across the generations known as transgenerational epigenetics (Rothstein, Harrell, \& Marchant, 2017). Yuan et al. (2017) showed that embryonic exposure to DBP disturbs testicular function in F1 and F3 generations by modulating Sertoli cells and spermatogenesis. The exposure to DBP modified the global DNA hypomethylation in the offspring with a decrease in follistatin like 3 (Fst/3) promoter hypomethylation (Yuan et al., 2017). Similarly, transient gestational exposure to atrazine induced differential DNA methylation regions in the F1-F3 generation spermatozoa (McBirney et al., 2017). Several recent studies have demonstrated the transgenerational inheritance of epigenetic alterations induced by embryonic exposure to environmental contaminants such as chlordecone, DDT, vinclozolin and DEHP leading to the deterioration of testicular architecture and sperm quality in F1 to F3 offspring (Ben Maamar et al., 2019; Doyle et al., 2013; GelyPernot et al., 2018; Skinner et al., 2019).

\section{MECHANISM OF ACTION OF ENVIRONMENTAL CONTAMINANTS}

Environmental contaminants can disrupt the male reproductive system via various mechanisms (Figure 1). Numerous studies have reported that environmental contaminants exert their reprotoxic effects by targeting the endocrine system (Buck Louis et al., 2018; Dankers et al., 2013; Jeng, 2014; McLachlan, 2016). Specifically, these contaminants are known to possess oestrogenic or antiandrogenic properties and thereby affect the hypothalamic-pituitary-gonadal (HPG) axis resulting in impairment of reproductive function. The process of gonadotropin-releasing hormone $(\mathrm{GnRH})$ release, gonadotropin secretion and subsequent downstream signalling are all potentially affected by environmental contaminants (Adoamnei et al., 2018; Rehman et al., 2018; Ren et al., 2019; Wisniewski et al., 2015). For instance, BPA, due to its antiandrogenic or antioestrogenic effect, has been reported to disturb the HPG axis through competitive inhibition at the receptor level resulting in hormonal imbalances and poor semen quality in men with higher urinary concentrations of BPA (Lassen et al., 2014). Disturbances in the HPG axis induced by environmental contaminants lead to changes in the levels of gonadotropins resulting in reduced serum $\mathrm{LH}, \mathrm{FSH}$ and testosterone levels (Adamkovicova et al., 2014; Rehman et al., 2018; Ren et al., 2019; Wisniewski et al., 2015).

Environmental contaminants are known to affect LH receptors (LHR) expression on Leydig cells resulting in the inhibition of testicular steroidogenesis (Wang, Chen, Ye, Zirkin, \& Chen, 2017). For instance, PFOS and PFOA have been reported to bind with LHR and inhibit testosterone synthesis (Foresta, Tescari, \& Di Nisio, 2018). Reduction in the LHRs and impairment of downstream signalling (decreased adenylate cyclase and CAMP), as well as inhibition of steroidogenic enzymes, are commonly reported following exposure to various environmental contaminants (Pogrmic-Majkic et al., 2016; Wang, Chen, Ye, Zirkin, \& Chen, 2017). Furthermore, decreased expression of StAR and inhibition of $\mathrm{P} 45 \mathrm{scc}_{\text {sc }}$, the rate-limiting steps of steroidogenesis, have been repeatedly reported as one of the mechanisms involved in the anti-steroidogenic effect of environmental contaminants (Hong et al., 2016; Kariyazono et al., 2015; Paul et al., 2017). Apart from the direct inhibitory effect on

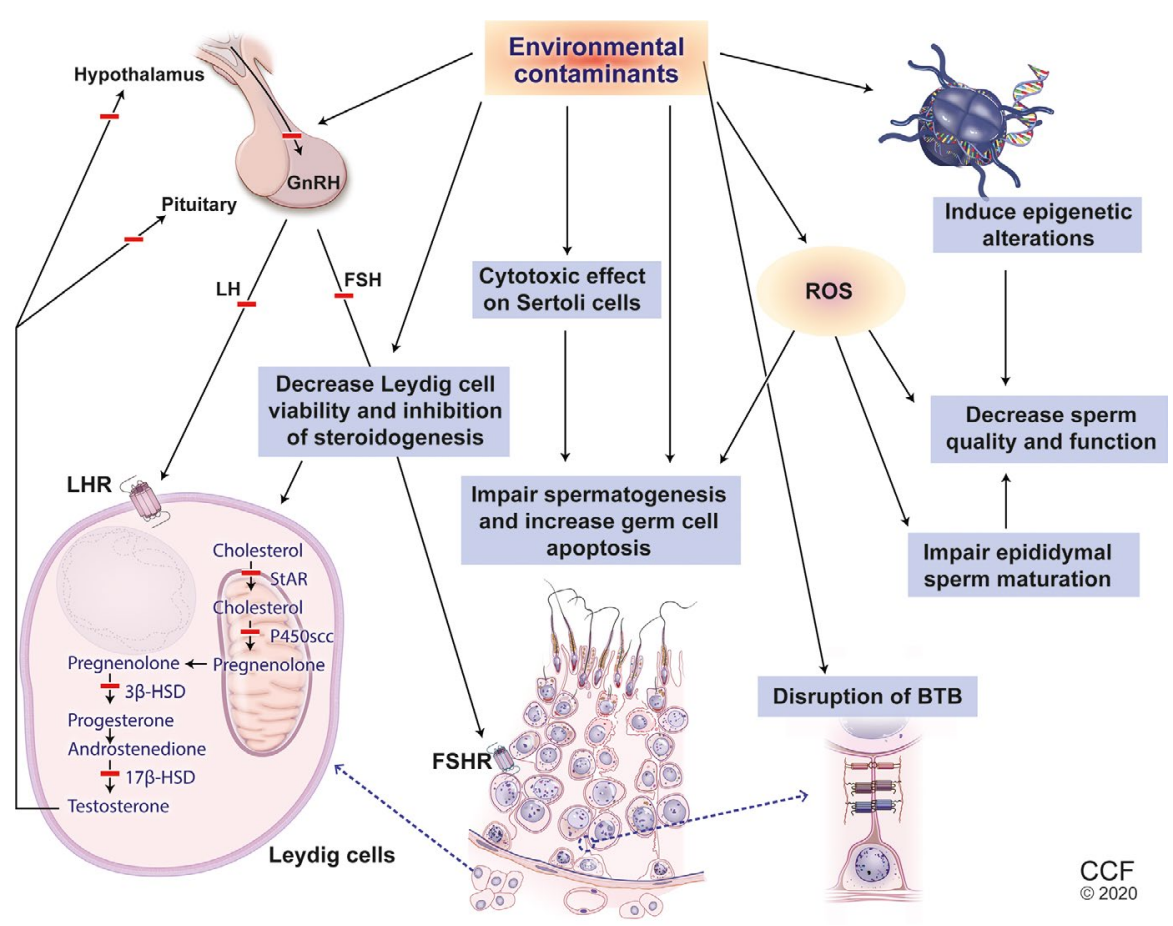

FIGURE 1 Mechanisms of action of environmental contaminants. Symbol $(=)$ indicates inference by environmental contaminants; $\mathrm{GnRH}$, gonadotropinreleasing hormone; $\mathrm{LH}$, luteinising hormone; $\mathrm{FSH}$, follicle-stimulating hormone; LHR, luteinising hormone receptor; StAR, steroidogenic acute regulatory protein; $\mathrm{P} 450_{\mathrm{scc}}, \mathrm{P} 450$ side-chain cleavage enzyme; $3 \beta-\mathrm{HSD}$, $3 \beta$-hydroxysteroid dehydrogenase; $17 \beta$-HSD, 17 $\beta$-hydroxysteroid dehydrogenase; FSHR, follicle-stimulating hormone receptor; ROS, reactive oxygen species; BTB, blood-testis barrier 
multiple steroidogenic enzymes, environmental contaminants are also known to inhibit the activities of these enzymes indirectly by inducing oxidative stress (Saradha et al., 2008; Sheweita, Al-Shora, $\&$ Hassan, 2016; Vaithinathan et al., 2008).

In addition to the steroidogenic pathway, the hormonal action of FSH, testosterone, oestradiol and their regulation by Leydig and Sertoli cells are essential for the maintenance of normal spermatogenesis. Environmental contaminants are reported to alter the spermatogenic cycle in rodent models resulting in increased germ cell apoptosis and decreased production of spermatozoa (McBirney et al., 2017; Zhang et al., 2018). In rodent models, environmental contaminants have been reported to induce germ cell apoptosis via FasFasL and mitochondrial-dependent cell death pathway (Vaithinathan et al., 2008; Wang \& Su, 2018). Germ cells are dependent on Sertoli cells for functional and nutritional support. Exposure to environmental contaminants leads to the destruction of germ cells by impairing the structure and function of Sertoli cells (Johnson, 2014; Rodríguez et al., 2017). Compounds with hormonal activity such as BPA and phthalates exert their effect on Sertoli cells by modulating the expression of steroid hormone receptors (Gao et al., 2015; Rehman et al., 2018). Studies have reported that BPA acts as an ER modulator and thus, affects the reproductive system by targeting ER $\alpha$ in Leydig cells or ER $\beta$ in Sertoli cells (Cariati et al., 2019; Wei et al., 2019). In fact, the expression of nuclear receptors was directly associated with BPA levels in infertile Italian men (La Rocca et al., 2015). These endocrine disruptors affect spermatogenesis by reducing Sertoli cell numbers, proliferation and interaction with spermatogonia, thereby increasing testicular cell apoptosis (Gao et al., 2015; Quan, Wang, Duan, Huang, \& Yang, 2017; Rehman et al., 2018). Aggregation of actin filaments in Sertoli cell and associated cytoskeletal disruption has been reported as one of the mechanisms in mediating the cytotoxic effect of BPA on Sertoli cell (Gao et al., 2015).

The gap and tight junctional proteins associated with BTB are one of the primary targets of contaminants (Gao et al., 2015). EDs such as MBP and BPA has been reported to reduce the expression of junctional proteins resulting in disruption of BTB via the AR-dependent pathway (de Freitas et al., 2016). Environmental contaminants such as PFOS and Aroclor 1,254 altered the levels of junctional proteins and increased the permeability of BTB via the p38-MAPK pathway (Jia et al., 2017; Qiu et al., 2016). Impairment in the structural and functional integrity of BTB compromises the immune- privileged status of the testis.

Oxidative stress is one of the main mechanisms involved in mediating the deleterious effects of environmental contaminants on male reproduction (Darbandi et al., 2018; Rehman, Jahan, Ullah, \& Winberg, 2019) as increased levels of ROS inhibit the activity of steroidogenic enzymes and activate apoptotic pathways in testis resulting in impairment of steroidogenesis and spermatogenesis, respectively (Quan et al., 2017; Sheweita et al., 2016; Shi, Sekulovski, MacLean, \& Hayashi, 2018). Furthermore, alterations in the antioxidant milieu of the epididymis induced by environmental contaminants negatively affect the sperm maturation process resulting in poor sperm quality (Adewoyin et al., 2017; Rahman et al., 2019). Elevated levels of ROS cause deleterious effects on spermatozoa by inducing lipid peroxidation and sperm DNA damage resulting in poor sperm motility, morphology and function (Ikhlas \& Ahmad, 2020; Rahman et al., 2015; Xie et al., 2019). Exposure to environmental contaminants impairs testicular and epididymal functions by inducing oxidative stress resulting in deterioration of sperm quality.

\section{8 | CONCLUSION}

Environmental contaminants consist of chemicals that cause deleterious effects on male reproduction. These chemicals affect male reproduction by interfering with the HPG axis, testicular spermatogenesis and steroidogenesis, epididymal maturation, steroid receptor mediating signalling, pro-oxidant/antioxidant balance and epigenetic regulation of testis and spermatozoa. Consequently, sperm production, quality, function and morphology are compromised, leading to male infertility. Modulation of steroid receptors, induction of oxidative stress and epigenetic alterations are the key mechanisms involved in mediating the deleterious effects of various environmental contaminants.

\section{ORCID}

Vaithinathan Selvaraju (D) https://orcid.org/0000-0003-4045-7710 Saradha Baskaran (iD https://orcid.org/0000-0002-4499-8680 Ashok Agarwal iD https://orcid.org/0000-0003-0585-1026 Ralf Henkel (iD https://orcid.org/0000-0003-1128-2982

\section{REFERENCES}

Adamkovicova, M., Toman, R., Cabaj, M., Massanyi, P., Martiniakova, M., Omelka, R., ... Duranova, H. (2014). Effects of subchronic exposure to cadmium and diazinon on testis and epididymis in rats. ScientificWorldJournal, 2014, 632581.

Adewoyin, M., Ibrahim, M., Roszaman, R., Isa, M., Alewi, N., Rafa, A., \& Anuar, M. (2017). Male infertility: The effect of natural antioxidants and phytocompounds on seminal oxidative stress. Diseases, 5(1), 9.

Adoamnei, E., Mendiola, J., Vela-Soria, F., Fernández, M. F., Olea, N., Jørgensen, N., ... Torres-Cantero, A. M. (2018). Urinary bisphenol A concentrations are associated with reproductive parameters in young men. Environmental Research, 161, 122-128.

Ahbab, M. A., Barlas, N., \& Karabulut, G. (2017). The toxicological effects of bisphenol $A$ and octylphenol on the reproductive system of prepubertal male rats. Toxicology and Industrial Health, 33(2), 133-146.

Akarca-Dizakar, S. O., Erdogan, D., Peker, T., Coskun Akcay, N., Turkoglu, I., Esmekaya, M. A., \& Omeroglu, S. (2019). Effects of co-administered melatonin, fructose and bisphenol A (BPA) on rat epididymis and sperm characteristics. Biotechnic and Histochemistry, 95, 1-9.

Albert, O., Nardelli, T. C., Lalancette, C., Hales, B. F., \& Robaire, B. (2018). Effects of in utero and lactational exposure to new generation green plasticizers on adult male rats: A comparative study with $\mathrm{Di}(2-$ Ethylhexyl) phthalate. Toxicological Sciences, 164(1), 129-141.

Anwer, F., Chaurasia, S., \& Khan, A. A. (2016). Hormonally active agents in the environment: A state-of-the-art review. Reviews on Environmental Health, 31(4), 415-433.

Aydin, Y., \& Erkan, M. (2017). The toxic effects of polychlorinated biphenyl (Aroclor 1242) on Tm3 Leydig cells. Toxicology and Industrial Health, 33(8), 636-645. 
Barakat, R., Seymore, T., Lin, P. P., Park, C. J., \& Ko, C. J. (2019). Prenatal exposure to an environmentally relevant phthalate mixture disrupts testicular steroidogenesis in adult male mice. Environmental Research, 172, 194-201.

Ben Maamar, M., Nilsson, E., Sadler-Riggleman, I., Beck, D., McCarrey, J. R., \& Skinner, M. K. (2019). Developmental origins of transgenerational sperm DNA methylation epimutations following ancestral DDT exposure. Developmental Biology, 445(2), 280-293.

Buck Louis, G. M., Smarr, M. M., Sun, L., Chen, Z., Honda, M., Wang, W., ... Kannan, K. (2018). Endocrine disrupting chemicals in seminal plasma and couple fecundity. Environmental Research, 163, 64-70.

Cai, J., Wang, C., Huang, L., Chen, M., \& Zuo, Z. (2013). A novel effect of polychlorinated biphenyls: Impairment of the tight junctions in the mouse epididymis. Toxicological Sciences, 134(2), 382-390.

Campos, P. D., Oliveira, I. M., Sena de Souza, J., Da Conceição, R. R., Giannocco, G., Chiamolera, M. I., ... Romano, R. M. (2019). Maternal bisphenol $A$ exposure disrupts spermatogenesis in adult rat offspring. Journal of Toxicology and Environmental Health, Part A, 82(3), 163-175.

Cariati, F., D'Uonno, N., Borrillo, F., Iervolino, S., Galdiero, G., \& Tomaiuolo, R. (2019). Bisphenol a: An emerging threat to male fertility. Reproductive Biology and Endocrinology, 17(1), 6.

Carlsen, E., Giwercman, A., Keiding, N., \& Skakkebaek, N. E. (1992). Evidence for decreasing quality of semen during past 50 years. BMJ, 305(6854), 609-613.

Carlsson, P., Breivik, K., Brorström-Lundén, E., Cousins, I., Christensen, J., Grimalt, J. O., ... Wöhrnschimmel, H. (2018). Polychlorinated biphenyls (PCBs) as sentinels for the elucidation of Arctic environmental change processes: A comprehensive review combined with ArcRisk project results. Environmental Science and Pollution Research International, 25(23), 22499-22528.

Cheng, C. Y., \& Mruk, D. D. (2011). Regulation of spermiogenesis, spermiation and blood-testis barrier dynamics: Novel insights from studies on Eps8 and Arp3. The Biochemical Journal, 435(3), 553-562.

Chianese, R., Viggiano, A., Urbanek, K., Cappetta, D., Troisi, J., Scafuro, M., ... Meccariello, R. (2018). Chronic exposure to low dose of bisphenol A impacts on the first round of spermatogenesis via SIRT1 modulation. Scientific Reports, 8(1), 2961.

da Cunha de Medeiros, P., Samelo, R. R., Silva, A. P. G., da Silva Araujo Santiago, M., Duarte, F. A., de Castro, Í. B., \& Perobelli, J. E. (2019). Prepubertal exposure to low doses of sodium arsenite impairs spermatogenesis and epididymal histophysiology in rats. Environmental Toxicology, 34(1), 83-91.

Dada, R., Kumar, M., Jesudasan, R., Fernandez, J. L., Gosalvez, J., \& Agarwal, A. (2012). Epigenetics and its role in male infertility. Journal of Assisted Reproduction and Genetics, 29(3), 213-223.

Dankers, A. C. A., Roelofs, M. J. E., Piersma, A. H., Sweep, F. C. G. J., Russel, F. G. M., van den Berg, M., ... Masereeuw, R. (2013). Endocrine disruptors differentially target ATP-binding cassette transporters in the blood-testis barrier and affect Leydig cell testosterone secretion in vitro. Toxicological Sciences, 136(2), 382-391.

Darbandi, M., Darbandi, S., Agarwal, A., Sengupta, P., Durairajanayagam, D., Henkel, R., \& Sadeghi, M. R. (2018). Reactive oxygen species and male reproductive hormones. Reproductive Biology and Endocrinology, 16(1), 87.

de Araujo Ramos, A. T., Diamante, M. A. S., de Almeida Lamas, C., Dolder, H., \& de Souza Predes, F. (2017). Morphological and morphometrical changes on adult Wistar rat testis caused by chronic sodium arsenite exposure. Environmental Science and Pollution Research International, 24(36), 27905-27912.

de Freitas, A., Ribeiro, M. A., Pinho, C. F., Peixoto, A. R., Domeniconi, R. F., \& Scarano, W. R. (2016). Regulatory and junctional proteins of the blood-testis barrier in human Sertoli cells are modified by monobutyl phthalate (MBP) and bisphenol A (BPA) exposure. Toxicology In Vitro, 34, 1-7.
Desdoits-Lethimonier, C., Albert, O., Le Bizec, B., Perdu, E., Zalko, D., Courant, F., ... Jegou, B. (2012). Human testis steroidogenesis is inhibited by phthalates. Human Reproduction, 27(5), 1451-1459.

Di Nisio, A., \& Foresta, C. (2019). Water and soil pollution as determinant of water and food quality/contamination and its impact on male fertility. Reproductive Biology and Endocrinology, 17(1), 4.

Dong, C., Cao, J., Cao, C., Han, Y., Wu, S., Wang, S., \& Wang, J. (2016). Effects of fluoride and aluminum on expressions of StAR and P450scc of related steroidogenesis in guinea pigs' testis. Chemosphere, 147, 345-351.

Donkin, I., \& Barres, R. (2018). Sperm epigenetics and influence of environmental factors. Molecular Metabolism, 14, 1-11.

Doyle, T. J., Bowman, J. L., Windell, V. L., McLean, D. J., \& Kim, K. H. (2013). Transgenerational effects of di-(2-ethylhexyl) phthalate on testicular germ cell associations and spermatogonial stem cells in mice. Biology of Reproduction, 88(5), 112.

Easley, C. A., Bradner, J. M., Moser, A., Rickman, C. A., McEachin, Z. T., Merritt, M. M., ... Caudle, W. M. (2015). Assessing reproductive toxicity of two environmental toxicants with a novel in vitro human spermatogenic model. Stem Cell Research, 14(3), 347-355.

Estill, M., Hauser, R., Nassan, F. L., Moss, A., \& Krawetz, S. A. (2019). The effects of di-butyl phthalate exposure from medications on human sperm RNA among men. Scientific Reports, 9(1), 12397.

Fang, Y., Ni, C., Dong, Y., Li, H., Wu, S., Li, X., ... Ge, R. S. (2018). In utero exposure to atrazine disrupts rat fetal testis development. Frontiers in Pharmacology, 9, 1391.

Ferguson, L., \& Agoulnik, A. I. (2013). Testicular Cancer and Cryptorchidism. Frontiers in Endocrinology (Lausanne), 4, 32.

Ferrara, F., Ademollo, N., Delise, M., Fabietti, F., \& Funari, E. (2008). Alkylphenols and their ethoxylates in seafood from the Tyrrhenian Sea. Chemosphere, 72(9), 1279-1285.

Foresta, C., Tescari, S., \& Di Nisio, A. (2018). Impact of perfluorochemicals on human health and reproduction: A male's perspective. Journal of Endocrinological Investigation, 41(6), 639-645.

Gao, Y., Mruk, D. D., \& Cheng, C. Y. (2015). Sertoli cells are the target of environmental toxicants in the testis - a mechanistic and therapeutic insight. Expert Opinion on Therapeutic Targets, 19(8), 1073-1090.

Ge, F., Zheng, W., Bao, S., Wu, K., Xiang, S., Chen, W., ... Ge, R.-S. (2018). In utero exposure to triphenyltin disrupts rat fetal testis development. Chemosphere, 211, 1043-1053.

Gely-Pernot, A., Hao, C., Legoff, L., Multigner, L., D'Cruz, S. C., Kervarrec, C., ... Smagulova, F. (2018). Gestational exposure to chlordecone promotes transgenerational changes in the murine reproductive system of males. Scientific Reports, 8(1), 10274.

Geoffroy-Siraudin, C., Perrard, M. H., Chaspoul, F., Lanteaume, A., Gallice, P., Durand, P., \& Guichaoua, M. R. (2010). Validation of a rat seminiferous tubule culture model as a suitable system for studying toxicant impact on meiosis effect of hexavalent chromium. Toxicological Sciences, 116(1), 286-296.

Governini, L., Guerranti, C., De Leo, V., Boschi, L., Luddi, A., Gori, M., ... Piomboni, P. (2015). Chromosomal aneuploidies and DNA fragmentation of human spermatozoa from patients exposed to perfluorinated compounds. Andrologia, 47(9), 1012-1019.

Guenther, K., Heinke, V., Thiele, B., Kleist, E., Prast, H., \& Raecker, T. (2002). Endocrine disrupting nonylphenols are ubiquitous in food. Environmental Science and Technology, 36(8), 1676-1680.

Hong, J., Chen, F., Wang, X., Bai, Y., Zhou, R., Li, Y., \& Chen, L. (2016). Exposure of preimplantation embryos to low-dose bisphenol A impairs testes development and suppresses histone acetylation of StAR promoter to reduce production of testosterone in mice. Molecular and Cellular Endocrinology, 427, 101-111.

Hou, X., Hu, H., Xiagedeer, B., Wang, P., Kang, C., Zhang, Q. I., ... Hao, W. (2020). Effects of chlorocholine chloride on pubertal development and reproductive functions in male rats. Toxicology Letters, 319, 1-10. 
Hu, G., Li, J., Shan, Y., Li, X., Zhu, Q., Li, H., ... Ge, R.-S. (2018). In utero combined di-(2-ethylhexyl) phthalate and diethyl phthalate exposure cumulatively impairs rat fetal Leydig cell development. Toxicology, 395, 23-33.

Hutson, J. M. (2000). Cryptorchidism and Hypospadias. NBK279106 [bookaccession]

Ikhlas, S., \& Ahmad, M. (2020). Acute and sub-acute bisphenol-B exposures adversely affect sperm count and quality in adolescent male mice. Chemosphere, 242, 125286.

Islam, R., Yoon, H., Kim, B. S., Bae, H. S., Shin, H. R., Kim, W.-J., ... Ryoo, H.-M. (2017). Blood-testis barrier integrity depends on Pin1 expression in Sertoli cells. Scientific Reports, 7(1),

Jeng, H. A. (2014). Exposure to endocrine disrupting chemicals and male reproductive health. Frontiers in Public Health, 2, 55.

Jia, X., Xu, Y., Wu, W., Fan, Y., Wang, G., Zhang, T., \& Su, W. (2017). Aroclor1254 disrupts the blood-testis barrier by promoting endocytosis and degradation of junction proteins via p38 MAPK pathway. Cell Death \& Disease, 8(5), e2823.

Johnson, K. J. (2014). Testicular histopathology associated with disruption of the Sertoli cell cytoskeleton. Spermatogenesis, 4(2), e979106.

Kariyazono, Y., Taura, J., Hattori, Y., Ishii, Y., Narimatsu, S., Fujimura, M., ... Yamada, H. (2015). Effect of in utero exposure to endocrine disruptors on fetal steroidogenesis governed by the pituitary-gonad axis: A study in rats using different ways of administration. Journal of Toxicological Sciences, 40(6), 909-916.

Kim, Y. B., Cheon, Y. P., Choi, D., \& Lee, S. H. (2019). Adverse effect of nonylphenol on the reproductive system in F2 male mice : A qualitative change? Development and Reproduction, 23(3), 255-262.

Kolatorova, L., Vitku, J., Vavrous, A., Hampl, R., Adamcova, K., Simkova, M., ... Duskova, M. (2018). Phthalate metabolites in maternal and cord plasma and their relations to other selected endocrine disruptors and steroids. Physiological Research, 67(Suppl 3), S473-S487.

Kumar, S. (2018). Occupational and environmental exposure to lead and reproductive health impairment: An overview. Indian Journal of Occupational and Environmental Medicine, 22(3), 128-137.

Kumar, V., Balomajumder, C., \& Roy, P. (2008). Disruption of LHinduced testosterone biosynthesis in testicular Leydig cells by triclosan: Probable mechanism of action. Toxicology, 250(2-3), 124-131.

La Rocca, C., Tait, S., Guerranti, C., Busani, L., Ciardo, F., Bergamasco, B., ... Mantovani, A. (2015). Exposure to endocrine disruptors and nuclear receptors gene expression in infertile and fertile men from Italian areas with different environmental features. International Journal of Environmental Research and Public Health, 12(10), 12426-12445.

Lassen, T. H., Frederiksen, H., Jensen, T. K., Petersen, J. H., Joensen, U. N., Main, K. M., ... Andersson, A.-M. (2014). Urinary bisphenol A levels in young men: Association with reproductive hormones and semen quality. Environmental Health Perspectives, 122(5), 478-484.

Lea, R. G., Byers, A. S., Sumner, R. N., Rhind, S. M., Zhang, Z., Freeman, S. L., ... England, G. C. W. (2016). Environmental chemicals impact dog semen quality in vitro and may be associated with a temporal decline in sperm motility and increased cryptorchidism. Scientific Reports, 6, 31281.

Li, L., Li, X., Chen, X., Chen, Y., Liu, J., Chen, F., ... Ge, R.-S. (2018). Perfluorooctane sulfonate impairs rat Leydig cell development during puberty. Chemosphere, 190, 43-53.

Li, R., Zhou, S. U., Zhu, H., Zhang, Z., Fang, J., Liu, P., ... Zhou, Z. (2019). Low dose of flurochloridone affected reproductive system of male rats but not fertility and early embryonic development. Reproductive Biology and Endocrinology, 17(1), 64.

Mantzouki, C., Bliatka, D., Iliadou, P. K., Margeli, A., Papassotiriou, I., Mastorakos, G., ... Goulis, D. G. (2019). Serum Bisphenol A concentrations in men with idiopathic infertility. Food and Chemical Toxicology, $125,562-565$
Mascarenhas, M. N., Flaxman, S. R., Boerma, T., Vanderpoel, S., \& Stevens, G. A. (2012). National, regional, and global trends in infertility prevalence since 1990: A systematic analysis of 277 health surveys. PLoS Medicine, 9(12), e1001356.

Maske, P., Dighe, V., Mote, C., \& Vanage, G. (2020). n-Butylparaben exposure through gestation and lactation impairs spermatogenesis and steroidogenesis causing reduced fertility in the F1 generation male rats. Environmental Pollution, 256, 112957.

McBirney, M., King, S. E., Pappalardo, M., Houser, E., Unkefer, M., Nilsson, E., ... Skinner, M. K. (2017). Atrazine induced epigenetic transgenerational inheritance of disease, lean phenotype and sperm epimutation pathology biomarkers. PLoS ONE, 12(9), e0184306.

McLachlan, J. A. (2016). Environmental signaling: From environmental estrogens to endocrine-disrupting chemicals and beyond. Andrology, 4(4), 684-694.

Men, Y., Zhao, Y., Zhang, P., Zhang, H., Gao, Y., Liu, J., ... Min, L. (2019). Gestational exposure to low-dose zearalenone disrupting offspring spermatogenesis might be through epigenetic modifications. Basic \& Clinical Pharmacology \& Toxicology, 125(4), 382-393.

Mota, P. C., Cordeiro, M., Pereira, S. P., Oliveira, P. J., Moreno, A. J., \& Ramalho-Santos, J. (2011). Differential effects of p, p'-DDE on testis and liver mitochondria: Implications for reproductive toxicology. Reproductive Toxicology, 31(1), 80-85.

Mruk, D. D., \& Cheng, C. Y. (2015). The mammalian blood-testis barrier: Its biology and regulation. Endocrine Reviews, 36(5), 564-591.

Muratori, M., \& De Geyter, C. (2019). Chromatin condensation, fragmentation of DNA and differences in the epigenetic signature of infertile men. Best Practice \& Research Clinical Endocrinology \& Metabolism, 33(1), 117-126.

Nassan, F. L., Mínguez-Alarcón, L., Williams, P. L., Dadd, R., Petrozza, J. C., Ford, J. B., ... Hauser, R. (2019). Urinary triclosan concentrations and semen quality among men from a fertility clinic. Environmental Research, 177, 108633.

Odermatt, A., Strajhar, P., \& Engeli, R. T. (2016). Disruption of steroidogenesis: Cell models for mechanistic investigations and as screening tools. Journal of Steroid Biochemistry and Molecular Biology, 158, 9-21.

Ogawa, Y., Itoh, M., Hirai, S., Suna, S., Naito, M., Qu, N., ... Mori, C. (2013). Cadmium exposure increases susceptibility to testicular autoimmunity in mice. Journal of Applied Toxicology, 33(7), 652-660.

Omran, G. A., Gaber, H. D., Mostafa, N. A. M., Abdel-Gaber, R. M., \& Salah, E. A. (2018). Potential hazards of bisphenol A exposure to semen quality and sperm DNA integrity among infertile men. Reproductive Toxicology, 81, 188-195.

Pant, N., Banerjee, A. K., Pandey, S., Mathur, N., Saxena, D. K., \& Srivastava, S. P. (2003). Correlation of lead and cadmium in human seminal plasma with seminal vesicle and prostatic markers. Human and Experimental Toxicology, 22(3), 125-128.

Pant, N., Mathur, N., Banerjee, A. K., Srivastava, S. P., \& Saxena, D. K. (2004). Correlation of chlorinated pesticides concentration in semen with seminal vesicle and prostatic markers. Reproductive Toxicology, 19(2), 209-214.

Paul, R., Molto, J., Ortuno, N., Romero, A., Bezos, C., Aizpurua, J., \& Gomez-Torres, M. J. (2017). Relationship between serum dioxin-like polychlorinated biphenyls and post-testicular maturation in human sperm. Reproductive Toxicology, 73, 312-321.

Pogrmic-Majkic, K., Fa, S., Samardzija, D., Hrubik, J., Kaisarevic, S., \& Andric, N. (2016). Atrazine activates multiple signaling pathways enhancing the rapid hCG-induced androgenesis in rat Leydig cells. Toxicology, 368-369, 37-45.

Qiu, L., Qian, Y., Liu, Z., Wang, C., Qu, J., Wang, X., \& Wang, S. (2016). Perfluorooctane sulfonate (PFOS) disrupts blood-testis barrier by down-regulating junction proteins via p38 MAPK/ATF2/MMP9 signaling pathway. Toxicology, 373, 1-12. 
Quan, C., Wang, C., Duan, P., Huang, W., \& Yang, K. (2017). Prenatal bisphenol a exposure leads to reproductive hazards on male offspring via the Akt/mTOR and mitochondrial apoptosis pathways. Environmental Toxicology, 32(3), 1007-1023.

Rahman, M. S., Kang, K. H., Arifuzzaman, S., Pang, W. K., Ryu, D. Y., Song, W. H., ... Pang, M. G. (2019). Effect of antioxidants on BPA-induced stress on sperm function in a mouse model. Scientific Reports, 9(1), 10584.

Rahman, M. S., Kwon, W. S., Lee, J. S., Yoon, S. J., Ryu, B. Y., \& Pang, M. G. (2015). Bisphenol-A affects male fertility via fertility-related proteins in spermatozoa. Scientific Reports, 5, 9169.

Rastogi, D., Narayan, R., Saxena, D. K., \& Chowdhuri, D. K. (2014). Endosulfan induced cell death in Sertoli-germ cells of male Wistar rat follows intrinsic mode of cell death. Chemosphere, 94, 104-115.

Rebourcet, D., Darbey, A., Monteiro, A., Soffientini, U., Tsai, Y. T., Handel, I., ... O'Shaughnessy, P. J. (2017). Sertoli cell number defines and predicts germ and leydig cell population sizes in the adult mouse testis. Endocrinology, 158(9), 2955-2969.

Rehman, H., Jahan, S., Ullah, I., \& Winberg, S. (2019). Toxicological effects of furan on the reproductive system of male rats: An "in vitro" and "in vivo"-based endocrinological and spermatogonial study. Chemosphere, 230, 327-336.

Rehman, S., Usman, Z., Rehman, S., AIDraihem, M., Rehman, N., Rehman, I., \& Ahmad, G. (2018). Endocrine disrupting chemicals and impact on male reproductive health. Translational Andrology and Urology, 7(3), 490-503.

Ren, J., Cui, J., Chen, Q., Zhou, N., Zhou, Z., Zhang, G.-H., ... Cao, J. (2019). Low-level lead exposure is associated with aberrant sperm quality and reproductive hormone levels in Chinese male individuals: Results from the MARHCS study low-level lead exposure is associated with aberrant sperm quality. Chemosphere, 244, 125402.

Riad, M. A., Abd-Rabo, M. M., Abd El Aziz, S. A., El Behairy, A. M., \& Badawy, M. M. (2018). Reproductive toxic impact of subchronic treatment with combined butylparaben and triclosan in weanling male rats. Journal of Biochemical and Molecular Toxicology, 32(3), e22037.

Rim, K. T. (2017). Reproductive toxic chemicals at work and efforts to protect workers' health: A literature review. Safety and Health at Work, 8(2), 143-150.

Rodríguez, H., Jara, H., Legua, S., Campos, D., Morales, J., \& EspinozaNavarro, O. (2017). Effects of cypermethrin on cytokeratin 8/18 and androgen receptor expression in the adult mouse Sertoli cell. Revista Internacional de Andrología, 15(2), 51-57.

Rodriguez-Mozaz, S., Marco, M. P., Lopez de Alda, M. J., \& Barceló, D. (2004). Biosensors for environmental applications: Future development trends. Pure and Applied Chemistry, 76(4), 723-752.

Rothstein, M. A., Harrell, H. L., \& Marchant, G. E. (2017). Transgenerational epigenetics and environmental justice. Environmental Epigenetics, 3(3), dvx011.

Saradha, B., Vaithinathan, S., \& Mathur, P. P. (2008). Single exposure to low dose of lindane causes transient decrease in testicular steroidogenesis in adult male Wistar rats. Toxicology, 244(2-3), 190-197.

Sayed, M. M., Hassanein, K. M. A., \& Senosy, W. (2014). Protective effects of thymoquinone and I-cysteine on cadmium-induced reproductive toxicity in rats. Toxicology Reports, 1, 612-620.

Sharpe, R. M., \& Skakkebaek, N. E. (1993). Are oestrogens involved in falling sperm counts and disorders of the male reproductive tract? Lancet, 341(8857), 1392-1395.

Sheweita, S. A., Al-Shora, S., \& Hassan, M. (2016). Effects of benzo[a] pyrene as an environmental pollutant and two natural antioxidants on biomarkers of reproductive dysfunction in male rats. Environmental Science and Pollution Research International, 23(17), 17226-17235.

Shi, M., Sekulovski, N., MacLean, J. A. 2nd, \& Hayashi, K. (2018). Prenatal exposure to bisphenol $A$ analogues on male reproductive functions in mice. Toxicological Sciences, 163(2), 620-631.
Singh, S., \& Singh, S. K. (2019). Prepubertal exposure to perfluorononanoic acid interferes with spermatogenesis and steroidogenesis in male mice. Ecotoxicology and Environmental Safety, 170, 590-599.

Siu, E. R., Mruk, D. D., Porto, C. S., \& Cheng, C. Y. (2009). Cadmiuminduced testicular injury. Toxicology and Applied Pharmacology, 238(3), 240-249.

Skakkebaek, N. E., Rajpert-De Meyts, E., Buck Louis, G. M., Toppari, J., Andersson, A.-M., Eisenberg, M. L., ... Juul, A. (2016). Male reproductive disorders and fertility trends: Influences of environment and genetic susceptibility. Physiological Reviews, 96(1), 55-97.

Skinner, M. K., Nilsson, E., Sadler-Riggleman, I., Beck, D., Ben Maamar, M., \& McCarrey, J. R. (2019). Transgenerational sperm DNA methylation epimutation developmental origins following ancestral vinclozolin exposure. Epigenetics, 14(7), 721-739.

Smith, L. B., \& Walker, W. H. (2014). The regulation of spermatogenesis by androgens. Seminars in Cell \& Developmental Biology, 30, 2-13.

Sprovieri, M., Feo, M. L., Prevedello, L., Manta, D. S., Sammartino, S., Tamburrino, S., \& Marsella, E. (2007). Heavy metals, polycyclic aromatic hydrocarbons and polychlorinated biphenyls in surface sediments of the Naples harbour (southern Italy). Chemosphere, 67(5), 998-1009.

Street, M., Angelini, S., Bernasconi, S., Burgio, E., Cassio, A., Catellani, C., ... Amarri, S. (2018). Current knowledge on endocrine disrupting chemicals (EDCs) from animal biology to humans, from pregnancy to adulthood: Highlights from a National Italian Meeting. International Journal of Molecular Sciences, 19(6), 1647.

Sugantha Priya, E., Sathish Kumar, T., Balaji, S., Bavithra, S., Raja Singh, P., Sakthivel, D., ... Arunakaran, J. (2017). Lactational exposure effect of polychlorinated biphenyl on rat Sertoli cell markers and functional regulators in prepuberal and puberal F1 offspring. Journal of Endocrinological Investigation, 40(1), 91-100.

Sullivan, R., \& Mieusset, R. (2016). The human epididymis: Its function in sperm maturation. Human Reproduction Update, 22(5), 574-587.

Sumner, R. N., Tomlinson, M., Craigon, J., England, G. C. W., \& Lea, R. G. (2019). Independent and combined effects of diethylhexyl phthalate and polychlorinated biphenyl 153 on sperm quality in the human and dog. Scientific Reports, 9(1), 3409.

Svechnikov, K., Savchuk, I., Morvan, M. L., Antignac, J. P., Le Bizec, B., \& Soder, O. (2016). Phthalates exert multiple effects on leydig cell steroidogenesis. Hormone Research in Paediatrics, 86(4), 253-263.

Swan, S. H., Elkin, E. P., \& Fenster, L. (1997). Have sperm densities declined? A reanalysis of global trend data. Environmental Health Perspectives, 105(11), 1228-1232.

Sweeney, M. F., Hasan, N., Soto, A. M., \& Sonnenschein, C. (2015). Environmental endocrine disruptors: Effects on the human male reproductive system. Reviews in Endocrine \& Metabolic Disorders, 16(4), 341-357.

Tavares, R. S., Escada-Rebelo, S., Correia, M., Mota, P. C., \& RamalhoSantos, J. (2016). The non-genomic effects of endocrine-disrupting chemicals on mammalian sperm. Reproduction, 151(1), R1-R13.

Tremblay, J. J. (2015). Molecular regulation of steroidogenesis in endocrine Leydig cells. Steroids, 103, 3-10.

Unuvar, T., \& Buyukgebiz, A. (2012). Fetal and neonatal endocrine disruptors. Journal of Clinical Research in Pediatric Endocrinology, 4(2), 51-60.

Vaithinathan, S., Saradha, B., \& Mathur, P. P. (2008). Transient inhibitory effect of methoxychlor on testicular steroidogenesis in rat: An in vivo study. Archives of Toxicology, 82(11), 833-839.

Verze, P., Cai, T., \& Lorenzetti, S. (2016). The role of the prostate in male fertility, health and disease. Nature Reviews Urology, 13(7), 379-386.

Vitku, J., Heracek, J., Sosvorova, L., Hampl, R., Chlupacova, T., Hill, M., ... Starka, L. (2016). Associations of bisphenol A and polychlorinated biphenyls with spermatogenesis and steroidogenesis in two biological fluids from men attending an infertility clinic. Environment International, 89-90, 166-173. 
Wang, M., \& Su, P. (2018). The role of the Fas/FasL signaling pathway in environmental toxicant-induced testicular cell apoptosis: An update. Systems Biology in Reproductive Medicine, 64(2), 93-102.

Wang, Y., Chen, F., Ye, L., Zirkin, B., \& Chen, H. (2017). Steroidogenesis in Leydig cells: Effects of aging and environmental factors. Reproduction, 154(4), R111-R122.

Wang, Y., Ni, C., Li, X., Lin, Z., Zhu, Q., Li, L., \& Ge, R. S. (2019). Phthalateinduced fetal leydig cell dysfunction mediates male reproductive tract anomalies. Frontiers in Pharmacology, 10, 1309.

Wang, Y. X., Wu, Y., Chen, H. G., Duan, P., Wang, L., Shen, H. Q., ... Pan, A. N. (2019). Seminal plasma metabolome in relation to semen quality and urinary phthalate metabolites among Chinese adult men. Environment International, 129, 354-363.

Wei, Y., Han, C., Geng, Y., Cui, Y., Bao, Y., Shi, W., \& Zhong, X. (2019). Maternal exposure to bisphenol A during pregnancy interferes testis development of F1 male mice. Environmental Science and Pollution Research International, 26(23), 23491-23504.

Wisniewski, P., Romano, R. M., Kizys, M. M. L., Oliveira, K. C., Kasamatsu, T., Giannocco, G., ... Romano, M. A. (2015). Adult exposure to bisphenol A (BPA) in Wistar rats reduces sperm quality with disruption of the hypothalamic-pituitary-testicular axis. Toxicology, 329, 1-9.

Woodruff, T. J., Carlson, A., Schwartz, J. M., \& Giudice, L. C. (2008). Proceedings of the summit on environmental challenges to reproductive health and fertility: Executive summary. Fertility and Sterility, 89(2), 281-300.

Wu, X., Liu, J., Duan, Y., Gao, S., Lü, Y., Li, X., ... Ge, R.-S. (2017). A shortterm exposure to tributyltin blocks leydig cell regeneration in the adult rat testis. Front Pharmacol, 8, 704.

Xiao, X., Mruk, D. D., Wong, C. K., \& Cheng, C. Y. (2014). Germ cell transport across the seminiferous epithelium during spermatogenesis. Physiology (Bethesda), 29(4), 286-298.
Xie, F., Chen, X., Weng, S., Xia, T., Sun, X., Luo, T., \& Li, P. (2019). Effects of two environmental endocrine disruptors di-n-butyl phthalate (DBP) and mono-n-butyl phthalate (MBP) on human sperm functions in vitro. Reproductive Toxicology, 83, 1-7.

Yang, Y., Yang, T., Liu, S., Cao, Z., Zhao, Y., Su, X., ... Hua, J. (2019). Concentrated ambient PM2.5 exposure affects mice sperm quality and testosterone biosynthesis. PeerJ, 7, e8109.

Yuan, B., Wu, W., Chen, M., Gu, H., Tang, Q., Guo, D., ... Wang, X. (2017). From the cover: Metabolomics reveals a role of betaine in prenatal DBP exposure-induced epigenetic transgenerational failure of spermatogenesis in rats. Toxicological Sciences, 158(2), 356-366.

Zhang, J., Hu, Y. I., Guo, J., Pan, R., Shi, R., Tian, Y., ... Gao, Y. U. (2018). Fenvalerate decreases semen quality in puberty rat through germ cell apoptosis. Andrologia, 50(9), e13079.

Zhang, P., Zhao, Y., Zhang, H., Liu, J., Feng, Y., Yin, S., ... Shen, W. (2019). Low dose chlorothalonil impairs mouse spermatogenesis through the intertwining of Estrogen receptor pathways with histone and DNA methylation. Chemosphere, 230, 384-395.

Zhou, Y., Sun, M., Tang, Y. E., Chen, Y. U., Zhu, C., Yang, Y., ... Tang, Z. (2020). Responses of the proteome in testis of mice exposed chronically to environmentally relevant concentrations of Microcystin-LR. Ecotoxicology and Environmental Safety, 187, 109824.

How to cite this article: Selvaraju V, Baskaran S, Agarwal A, Henkel R. Environmental contaminants and male infertility: Effects and mechanisms. Andrologia. 2021;53:e13646. https:// doi.org/10.1111/and.13646 